\title{
Unexplained hypothermia and bradycardia in two pediatric patients with Wegener's granulomatosis
}

\author{
Lianne M. Geerdink • Linda Koster-Kamphuis • \\ Elisabeth A. M. Cornelissen - Michèl A. Willemsen • \\ Nicole C. A. J. van de Kar
}

Received: 29 June 2010 /Revised: 21 July 2010 / Accepted: 26 July 2010 / Published online: 22 August 2010

(C) The Author(s) 2010. This article is published with open access at Springerlink.com

Sirs,

We report remarkable symptoms of Wegener's granulomatosis (WG), which might occur more often than reported so far. Two patients (13 and 16 years old) with acute renal failure due to WG developed simultaneous hypothermia $\left(<36.5^{\circ} \mathrm{C}\right)$ and bradycardia $(<60 \mathrm{bpm})$ during the first weeks of treatment with intravenous pulse methylprednisolone (IPM), cyclophosphamide (CYC), hemodialysis (HD), and therapeutic plasma exchange (TPE). In both patients, rapidly progressive pauci-immune glomerulonephritis was confirmed by renal biopsy, and antineutrophil cytoplasmic antibody (ANCA)-serology was positive. They received 3-day IPM therapy $\left(1 \mathrm{~g} / 1.73 \mathrm{~m}^{2}\right)$, followed by prednisolone and cyclophosphamide (CYC) (2 mg/kg/day). Hemodialysis and TPE were started immediately. Soon after onset of treatment, hypothermia $\left(34.9^{\circ} \mathrm{C}\right)$ and bradycardia $(40 \mathrm{bpm})$ were observed (Fig. 1). Electrocardiogram showed a sinus bradycardia; endocarditis was excluded. Serum electrolyte and calcium levels were within reference ranges; thyroid function was normal. There were no signs of infection. Funduscopy showed no papilledema or renal vascular abnormalities, and neurological examination was normal.

L. M. Geerdink $(\bowtie) \cdot$ L. Koster-Kamphuis •

E. A. M. Cornelissen - N. C. A. J. van de Kar

Department of Paediatric Nephrology,

Radboud University Nijmegen Medical Centre,

PO Box 9101, 6500 HB Nijmegen, The Netherlands

e-mail: lgeerdink@gmail.com

M. A. Willemsen

Department of Paediatric Neurology,

Radboud University Nijmegen Medical Centre,

Nijmegen, The Netherlands
Cerebral magnetic resonance imaging (MRI) showed no signs of cerebral granulomas or vasculitis.

In one patient, hypothermia and bradycardia remained asymptomatic and resolved spontaneously over 4 weeks. The other patient developed generalized seizures. Additional diagnostics (cerebral computed tomography and cerebrospinal fluid) showed no abnormalities. This patient also recovered spontaneously over several weeks.

We have not been able to explain these conspicuous findings. To the best of our knowledge, hypothermia has not been reported as an adverse effect of treatment with IPM or CYC. Bradycardia in IPM patients, however, has been described [1], but remarkably, in both our patients, bradycardia continued for weeks after IPM treatment. In CYCtreated patients, arrhythmias have been described, but only when high doses exceeding $144 \mathrm{mg} / \mathrm{kg}$ were administered [2].

In only $4-9 \%$ of the WG patients is the central nervous system (CNS) involved at onset [3], possibly due to contiguous extension of sinus granulomas. In our patients, no granulomas were seen by cerebral imaging. Neurological abnormalities may also occur as a direct consequence of small-vessel cerebral vasculitis. However, in one patient, hypothemia and bradycardia were the only neurologic abnormalities. Transient involvement of the CNS by vasculitis at the level of the hypothalamus causing hypothermia and secondary bradycardia alone is unlikely, but it cannot be excluded. In conclusion, unexplained, self-limiting, prolonged hypothermia and bradycardia can occur during the first weeks of treatment of WG. The pathogenesis and clinical relevance needs to be addressed in further studies.

Open Access This article is distributed under the terms of the Creative Commons Attribution Noncommercial License which permits any noncommercial use, distribution, and reproduction in any medium, provided the original author(s) and source are credited. 
Fig. 1 Body temperature $\left({ }^{\circ} \mathrm{C}\right)$ and heart rate $(\mathrm{bpm})$ in patient 1 with rapidly progressive glomerulonephritis due to Wegener's granulomatosis (WG) during the first weeks of treatment. Normal range in grey. bpm beats per minute, $I P M$ intravenous pulse methylprednisolone, TPE therapeutic plasma exchange, $H D$ hemodialysis

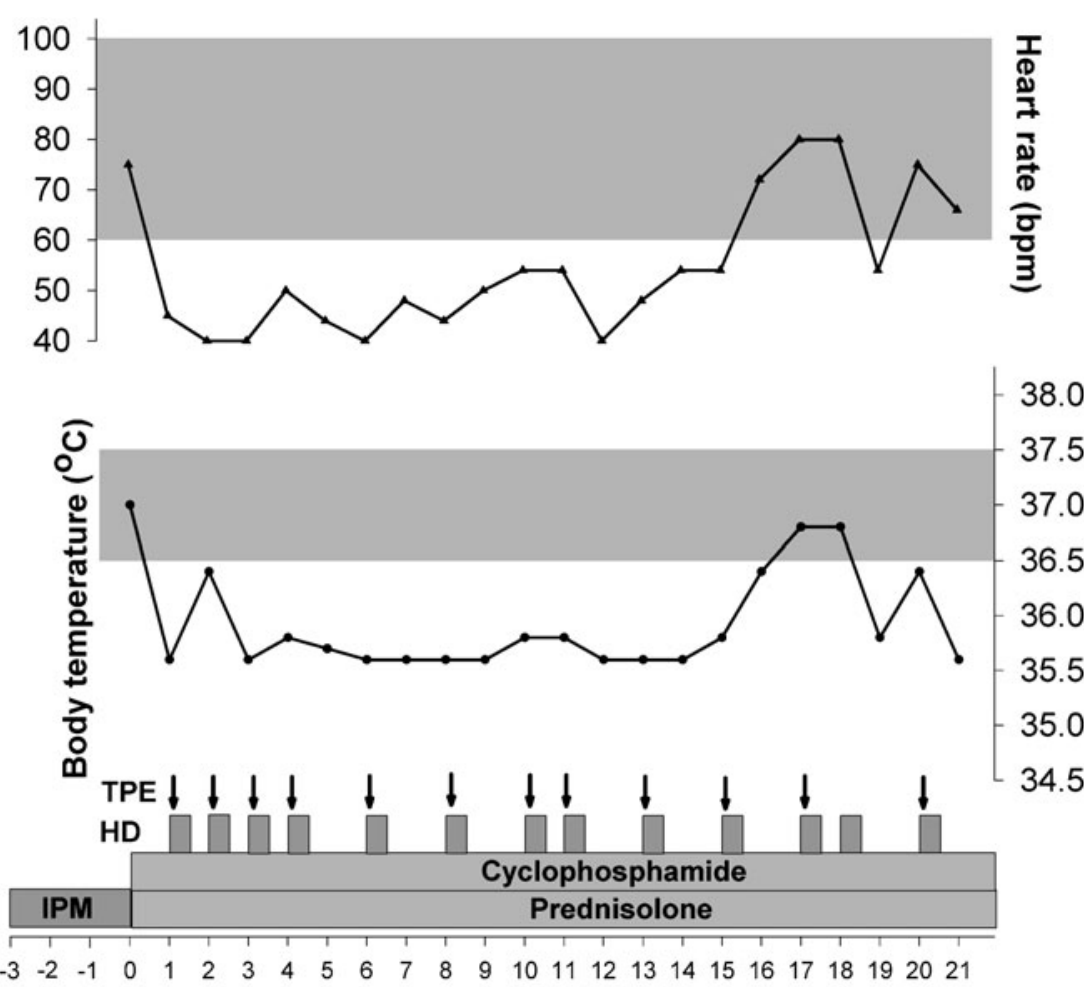

Days of admittance

\section{References}

1. Akikusa JD, Feldman BM, Gross GJ, Silverman ED, Schneider R (2007) Sinus bradycardia after intravenous pulse methylprednisolone. Pediatrics 119:778-782
2. Langford CA (1997) Complications of cyclophosphamide therapy. Eur Arch Otorhinolaryngol 254:65-72

3. Rottem M, Fauci AS, Hallahan CW, Kerr GS, Lebovics R, Leavitt RY, Hoffman GS (1993) Wegener granulomatosis in children and adolescents: clinical presentation and outcome. J Pediatr 122:26-31 